\title{
Music Computer Technologies in Music Studies at School of the Digital Age (Aspect of Musical Notation)
}

\author{
Irina B. Gorbunova ${ }^{1}$ and Hellene Hiner ${ }^{2}$ \\ ${ }^{1}$ Department of Information Technology, Institute of Computer Science and Technological Education of the \\ Herzen State Pedagogical University of Russia and Educational and Methodological Laboratory Music \\ Computer Technologies of the Herzen State Pedagogical University of Russia, St. Petersburg \\ ${ }^{2}$ Music Vision International LLC, musicologist, founder and Director of Music Vision International LLC, \\ author of the 'Soft Way to Mozart' system, Houston, USA, Houston
}

\begin{abstract}
The development of music computer technologies in the late 20s - early 21 st century has significantly expanded the ways of obtaining information. High-tech information educational environment requires the search for new approaches and fundamentally new systems of education in the School of the Digital Age. The global applicability of the music computer technologies (MCT), provide new, in fact, limitless possibilities of selfrealization, stimulate the rapid development of intelligence, raising training to a new level; compatibility with traditional musical technology creates conditions for the continuity of musical eras and styles, their interpenetration and synthesis, reinforcing the interest in musical culture in general. In musical practice the big distribution has acquired a new class of musical instruments that includes keyboards, synthesizers, workstations, multimedia computers etc. Among the main objectives worked up by contemporary pedagogics in music, the authors focus their attention on the actual possibilities of digital technologies in enriching and enhancing the role of traditions that have been crystallized in practice of musical pedagogics for many centuries. The authors of the article discuss opportunities of music computer technology system for learning music and describe the experience of their use in their research and pedagogical practice with using the 'Soft Way to Mozart 'system
\end{abstract}

Keywords: music computer technologies, musical education, musical notation, 'Soft Way to Mozart' system.

\section{Introduction}

Imagine math lessons in schools where your child is taught the biographies of great mathematicians and the ability to visually distinguish an equation from multiplication. And on exams they are asked to point their finger at a line where there is a multiplication or subtraction sign. In this case, the study of numbers is introductory and takes place somewhere in the third grade.

Imagine that in reading class your child is taught poems and songs. They learn to distinguish iambic from chorea by ear. They listen to poetry performed by actors without any introduction to the letters A, B, or C. How productive would that be? Today, that is how music is generally taught in most public schools.

Music education in school is an "autistic subject," in a metaphoric meaning of the word. The major problem of most music curricula is a lack of focus.

We see it as one of the biggest global problems of our contemporary society. Here is why:

The number, the letter, the music note - this is the very foundation of the world of words, numbers and sounds. Humanity has mastered the numbers and letters. But the music notes are completely out of focus.

Note (lat. Nōta - "sign," "label") - a graphic image of a musical sound, as well as the sound itself. A note has three main parameters: a pitch (the number of vibrations of a sound wave), a position on the music staff and a duration. These three elements are one, but in school are taught separately from the start. 
Singing songs in general music lessons has nothing to do with reading notes from the staff. Learning the rhythm and meter with the help of percussion instruments is in no way connected with discovering the number of sound vibrations or reading the notes from the staff.

Such musical activities generate nothing but chaos. In this complete chaos, children in music lessons do not learn to perceive a note in its trinity. Instead, we develop in children a sense of uncertainty, destructiveness, and unpredictability of the consequences of a particular action. Some students in this chaos learn some skills not because of, but in spite of, the lessons. Most of the student body toils in boredom and confusion through the process of learning everything and nothing.

Thanks to such lessons of "music," we instill in children the perception of the world not as a single and harmonious whole, where all elements are interconnected, interdependent. We instill in children a picture of the world in which there are many disconnected pieces of puzzles, and you are all alone -- the center of the Universe. In the world that we program for our kids in public schools, we develop their self-centered attitude with no regard for other living creatures.

The musical chaos in our heads fills most of our consciousness every minute. Whether we like it or not, it acts on a subconscious level on each of us. Without teaching students to focus on a note as a trinity of one, the harmony and interrelation of the elements of the world become impossible for an unprepared person to recognize. Especially a child!

Instead of a means of educating and developing spiritually, music becomes the secret weapon of manipulation. Children drink alcohol and do drugs at concerts of this type of music. This is not what music is supposed to do for people.

All pop culture, advertising, and mass media are built on using music as the main emotional manipulator.

Divide and rule. This slogan fits best today in teaching "music" in schools, where there is no focus on the main element of music - the note. Separating the trinity of the sound of notes and duration into distinct elements and depriving children of the elementary opportunity to become musically literate, we form in them anything but complete, creative souls. Not seeing and not perceiving the harmony and interrelations of all the elements of music, we destroy nature, the land on which we live, ourselves. And each other.

In fact, it is with the help of the trinity of the main element of music that the concept of the Trinity can be explained to children as the union of vibrations. The Bible helps us to understand the true. Divine property of sound, in which the elements of vibration, sign and a certain duration (birth -- life on earth -- the completion of life on earth) are one.

And we ask you to note that in this context the Bible is related not so much to religion, as to the spiritual, multidimensional perception of the world, as a whole and, with us in it, as the elements of complete harmony.

We are sure that starting a child learning music from a note, a child would be able to quickly determine his spiritual orientations. In each of us there are both the Earthly and the Heavenly. Depriving the person of the note, we deprive him from making a choice.

Why is it important for each of us?

General music at school is a state-required subject. With all the public rantings about the "luck of funds," a huge amount of money is allocated annually to keep music lessons in public schools out of state budgets. The schools' loss of all these funds is not for the benefit but to the detriment of our children.

Why is music education that doesn't focus on the music note harmful for our children?

Without notes, music lessons at school teach children that the world is chaotic and that to break through in this chaos is the only purpose of existence.

Musical notation and communication one-on-one with each note teach the child the value of every moment because he visually experiences the beginning, the development, and the completion of each sound. Seeing the 
music notes together in a piece, the child learns to treat life as an invaluable gift in which the creation of anything is a project. There is a beginning to the project - a development and a completion.

Without the ability to read a musical text, children waste hours of their time pretending to learn something without ever actually learning a thing, a habit that becomes the norm for their attitude toward life.

The industry of celebrities and stars is the crest of this dirty "musical" wave that has swallowed up modern society. Departure from the trinity of the notes has over-simplified and vulgarized the language of music. The scarcity of focus on the note is compensated for by all the mindless visual effects that hold a person's attention at any cost.

This is a sign of the extinction of the ability of society to adequately perceive higher musical vibrations, to be able to focus, and to develop memory and a longer attention span.

What we today call "general music" in schools requires an immediate reappraisal and revision to avoid more serious $\mathrm{C}$

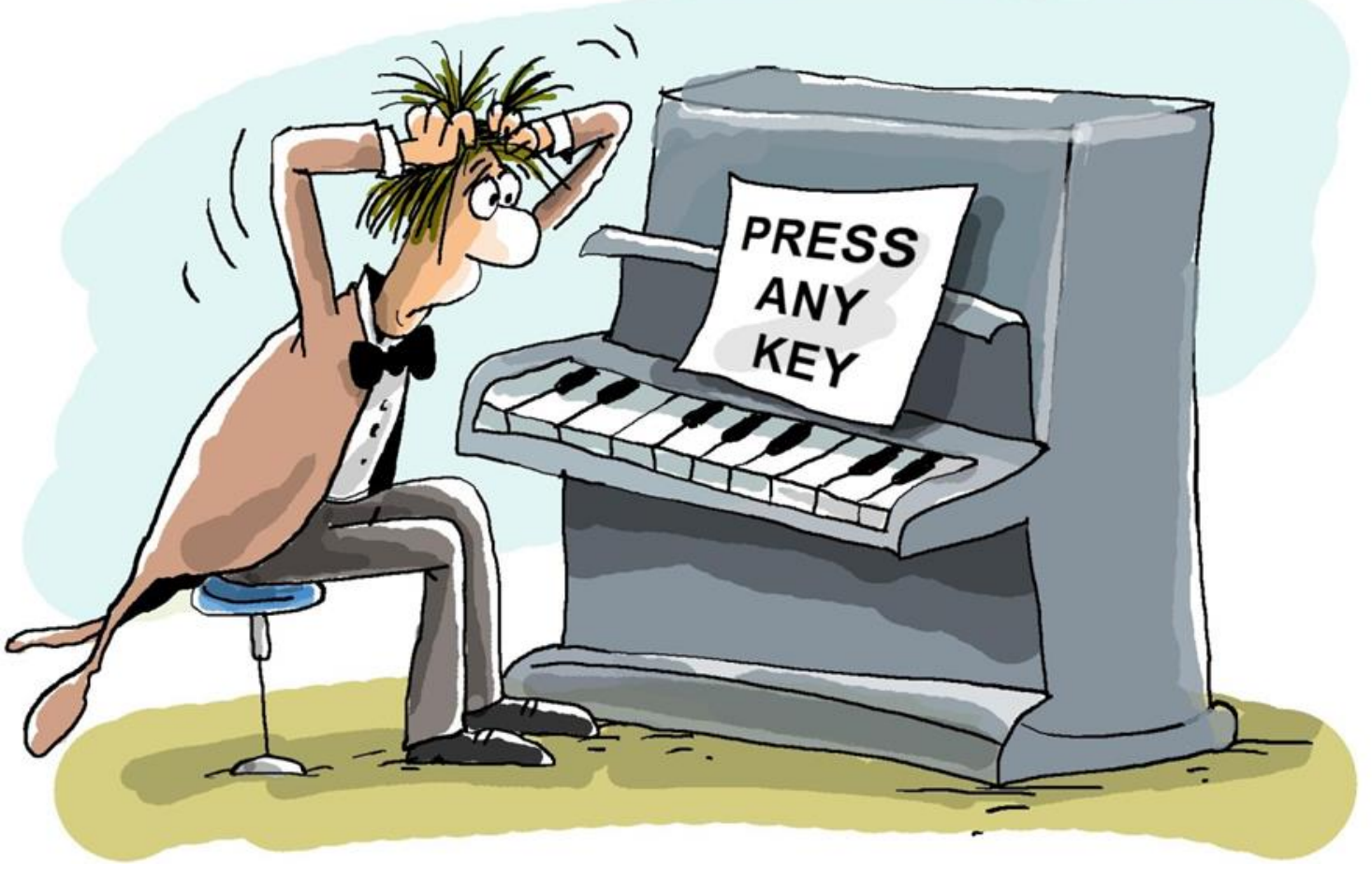

\section{A New Class Of Musical Instruments}

In musical practice the big distribution has acquired a new class of musical instruments that includes keyboards, synthesizers, workstations, multimedia computers, etc. Built on the basis of digital technology these tools are characterized by considerable expressive resources, which opens up broad prospects for their application in music education $[1 ; 2 ; 3]$. New opportunities allowed us to carry out with the help of such tools not only recording, but also performing tasks. It is not by chance that with the development of the music computer technologies (MCT), this auditory experience has become the Foundation for many developments in the didactic direction. The creation of musical compositions with the use of new possibilities of MCT is already widely included in the practice of professional composers. The ways of realization of the concept of musicalcomputer pedagogical education, allowing us to change the level of training of the teacher-musician at different stages of training, are proved in a number of scientific and pedagogical researches $[4 ; 5 ; 6$, etc.].

In the software of professional activities of the contemporary musician and the possibilities of contemporary electronic musical instruments, the IT accumulated over the centuries in music and the art of music making has 
been fully and completely embodied. The understanding of the fact that a specialized musical computer (MC) is becoming a new multi-functional poly-timbral instrument of a musician is being formed. A lot of works are devoted to the musical computer, electronic musical synthesizer and various aspects of their functioning in the contemporary artistic and creative environment (see, for example, [7; 8, 9, etc.]).

\section{Education System of Music Computer Technologies}

The complex innovative educational system 'Music Computer Technologies in Teacher-Musician Training' developed in the educational and methodical laboratory 'Music computer technologies' at the Herzen State Pedagogical University of Russian [10], based on the best traditions of the domestic classical music education, as well as innovative foreign experience and contemporary MCT [11], developing both the actual music and information technology education, will indispensably affect the problems of music writing and social aspects of the process of computerizing of art education in general $[12 ; 13 ; 14 ; 15$, etc.]. The principles underlying the creation of the methodical system are the basic ones for the formation of a new subject area in musical and pedagogical education, the possibility of which is due not only to the emergence and development of the international art, but also to the preservation of crystallized written traditions of musical culture. Their existence is fundamental to the formed at the present stage of the professional activities not only musicians, working with MCT (sound engineers, sound designers, sound producers, performers on synthesizers and MIDI-instruments, etc.), not just programmers (developers in the field of electronic music systems), but also music teachers, for whom contemporary technologies offer new possibilities in the solution of didactic problems $[16 ; 17 ; 18$ and others].

The authors see one of the main tasks of pedagogical research in revealing the didactic features of the use of MCT, the possibility of their application in the musical education and education of the younger generation on the basis of classical music, traditional approaches to the methods of transmission the products centuries-old musical culture. It is important that the passion for external, new digital effects and opportunities not only contributed to the bright and colorful "hot" impressions in communication with the art of music [19], but also developed critical thinking, worked on the development of intellectual and cultural growth of students, including the use of music and computer technology as a means of teaching visually impaired students [20;21].

Today, it is clear that the use of the MCT has great potential for writing, performing, researching music and music education and education; that this process should not be feared of, but rather should be supported and actively participated in. So, to the often sounding question: "What is the reason for substituting the gifted musicians by 'machines', taking art alive one to the last plan, and thus lowering the aesthetic value of music art?", composer and musicologist, teacher and scientist, Prof., Dr. Yu. N. Rags, who worked in various fields of music science (among them: problems of music aesthetics, music acoustics, research in the field of music psychology, the interaction of composer and performing arts, the study of the role and place of information technology in music and music education, the role of electronic and computer music in the contemporary musical and artistic space, etc.), replied: "But in this regard, no one sets the task. It is known that the computer and electronic sound fills the now advertising, music videos, television and radio broadcasts, films etc. Their quality is not always satisfying. In this area, therefore, there is a need to prepare real professionals who could really raise the artistic level of art. And schools should not give up the case, and, if possible, to lead them" [22, p. 202]. Calling for the unification of musicians, musicology theories, knowledge about music, Rags says about the need to unite the musicians themselves: "To unite the interests of musicians working in secondary schools and in special music schools in all specialties and at all levels of education (in the children's musical school, comprehensive schools or colleges, Universities)" and "to use the rich opportunities of new IT and in the methodological development of the system of music education" [23, pp. 65, 67], to establish mutual understanding between representatives of various areas of musical research.

We would like to emphasize that today information technology is a powerful educational resource. With the help of the Internet you can exchange views, communicate with people from any country, anywhere in the world. 
But we are not yet using many of the new instrumental capabilities of the digital age in music education, among them are the benefits of interactive dialogue with a music computer to develop and improve music skills that are applicable in everyday academic practice.

We present the results of our pedagogical research aimed at studying the possibility of using both auditory and visual features of students' perception of the musical text in the field of general music education on the example of an interactive learning system 'Soft Way to Mozart', developed by H. Hiner in 2002 and tested in music schools and studios in 52 countries. Along with such interactive educational programs as 'Music in Digital Space', 'Music and Informatics', 'Murzilka: The Lost Melody', 'Clifford: Guess the Melody', 'Music Class: Play and Learn', 'Ear Master School', 'Ear Power', 'Sight-Singing Trainer', etc., the program 'Soft Way to Mozart' also uses a wide range of media features, putting at the forefront the fundamental principles and scientific achievements of the Russian School of Music [24; 25; 26].

\section{The Pedagogical System 'Soft Way to Mozart'}

A feature of the 'Soft Way to Mozart' system is the fact that it is actively implemented in the music-text field (individual skills, especially with musical text), allowing us to integrate direct audio experience with the possibility of "detached" analysis of musical notation. This allows us to enrich the art education and education of students, it promotes their spiritual and moral development, it allows us to actively introduce health-saving educational technologies in conjunction with the principles of the highest educational standards. Compared with other schools of the world, such as Suzuki, Yamaha, Kindermusik and some other methodical schools of Bastien, Alfred, Faybers, etc., only the Russian School of Music is based on the developed and tested for centuries academic basis. Most of the above schools and methodological systems are not based on the academic principles of teaching solfeggio, which in the conditions of the Russian School of Music is the cornerstone of the musical and cultural development of beginners (gradual, continuous and systematic development of specific skills, such as writing musical dictations, listening to and reading musical text, transposing, the basics of harmony and applied music theory, etc.).

The central part of the 'Soft Way to Mozart' system is specialized software, the necessary condition for the functioning of which is the connection with a digital keyboard musical instrument, carried out by means of a MIDI-interface.

The choice of a keyboard instrument such as a clavier, a synthesizer, a MIDI-controller or a piano (in the 'Soft Way to Mozart' system we use digital keyboard instruments) was due to the crystallized traditions of classical music education. It is the keyboard that is able to convey the multi-voice palette of the musical fabric most accurately. Keyboard instruments have been the sound equivalent of a multi-voice sounding space for the last few centuries. Many genres of musical culture, are based on the use of scores, they are translated into the format of the clavier for wider use in the study of musical material and teaching IT.

The most important feature of the MCT is the possibility of direct and simultaneous interaction of not only all multimedia structures, but also the algorithm of interaction of these structures with human perception. Digital media technologies have raised the process of both visual and auditory perception of the music stream to a new level: the level of a high degree of interaction. The integration of "hot", direct experience with "cold", analytical have become became possible due to the fact that "live" time and experience in "live time" have become a unit managed, not spontaneous, as it was before. In the 'Soft Way to Mozart' system, a person can be in the "live time" field and outside it by pressing the synthesizer key. This allowed us to enrich the experience of the auditory perception with the possibilities of visual analysis, as well as rethink the studied material and evaluate it with the help of the built-in statistical analysis.

The possibilities of pedagogy, crystallized in everyday musical pedagogical practice-registration of sound and rhythmic errors, metric and coordination stability, speed of visual, tactile and classroom reaction when communicating with musical text were initially taken into account in the development of the 'Soft Way to Mozart' system. The tested media means inherent in MCT (computer graphics, sound and graphic cards, 
animation, interactive ways of communication, etc.) have also found their place in this computer-didactic system. The selection of the keyboard as part of a single system of MCT is also due to the visual identity existing between the keyboard and the music space.

One of the main tasks of training in this program is to determine the level of understanding of the role of the IT and multimedia digital tools in teaching skills of playing keyboard instruments, the development of listening and playing from sight.

The thematic plan of the professional development program includes the study of the following topics:

1. The nature of human musical abilities. The role of motivation in music teaching and interactive network technologies of music teaching. MCT. The analysis of the different schools of the world from the point of view of the approach to teaching music. The role of the Russian School of Music in world music education. Interactivity as the foundation of motivation in learning. Features of human cognitive functions. The role of cognitive inquiry in the development of knowledge and skills.

2. The basic principles of the course 'Soft Way to Mozart'. Neuropsychological and physiological features of human development in the process of learning music. The role of voice in music teaching. Application of the vocal nature of music in the development of hearing and voice using the 'Soft Way to Mozart' system. Development of "musical vision". Features of visual perception of the musical text and ways to improve the "reading" of music using the 'Soft Way to Mozart' system. Statistical analysis of skills development using the measurement system of 'Soft Way to Mozart'. Music and linguistics.

3. The main components of the interactive learning system 'Soft Way to Mozart'. The components of the 'Soft Way to Mozart' system: specialized software, computer and synthesizer interconnection. Features of the 'Soft Way to Mozart' system in different conditions and with different groups of students.

\section{Conclusion}

On the example of the 'Soft Way to Mozart' system it was possible to trace how the MCT are able to integrate the established pre-digital psychological modalities with new multimedia capabilities. New multimedia modules in a live time mode are easily integrated with the procedural nature of the musical language and they allow us to present the musical notation in a new, dynamic quality. The direct perception of the musical flow is combined with analytical, which greatly enhances the didactic possibilities and translates the cognitive experience of students to a new level of development. The synthesis of MCT and modified musical notation opens up new didactic possibilities in the use of musical notation, the actualization of its use in the Digital Age [27]. Digital enrichment of musical notation using the 'Soft Way to Mozart' system can help to solve a number of problems of music education in the 21th century and promote a new stage of music development as one of the most important facets of the world comprehension.

\section{References}

[1] Gorbunova, I. B. Information Technologies in Music. V. 2. Music Synthesizers: course book. St. Petersburg: Publishing House of the Herzen State Pedagogical University of Russia, 2010.

[2] Gorbunova, I. B. Information technology in music and music education. The World of Science, Culture, Education, vol. 63, no. 2, $206-210,2017$.

[3] Gorbunova, I. B. New Tool for a Musician, 15th International Conference on Education, Economics, Humanities and Interdisciplinary Studies (EEHIS-18). International Conference Proceedings, ed.: Prof., Dr. Rahim Ahmadi, Prof. Kazuaki Maeda, Prof. Dr M. Plaisent. Paris (France), 144 - 150, 2018.

[4] Gorbunova, I. B. Information technology in music and integrated model of semantic space. Scientific-technical Bulletin of Saint-Petersburg State Polytechnic University. Humanities and Social Sciences, 4 (208), 152-161, 2014. 
[5] Gorbunova, I. B. Music computer technologies as a new educational creative environment. In G.A. Bordovsky (Chair), Topical Issues of Contemporary University Education. Materials of the 11th Russian-American Scientific and Practical Conference, St. Petersburg, Russia, 163 - 167, 2008.

[6] Gorbunova, I. B. Musical instruments as synthesizers of musical sound. Society: Philosophy, History, Culture, 2, 89 93, 2016.

[7] Gorbunova, I. B. Information Technology in Music. V. 3. Music Computer: course book. St. Petersburg: Publishing House of the Herzen State Pedagogical University of Russia, 2011.

[8] Gorbunova, I. B. Music Computer: monograph, Saint Petersburg: Publishing House SMIO Press, 2007.

[9] Gorbunova, I. B. Music computer as a new tool of the teacher-musician at the School of the Digital century. Theory and Practice of Social Development, 11, 254-257, 2015.

[10] Gorbunova, I. B.. Musical-computer technology: the laboratory. Mediamusic, 1: 5-7, 2012. Retrieved from http://mediamusic-journal.com/Issues/1_5.html

[11] Gorbunova, I.B. The phenomenon of music computer technologies as a new medium of musical education. Proceedings of the Herzen State Pedagogical University of Russia, 4 (9), 123 - 138, 2004.

[12] Gorbunova, I. B. Computer science and computer music technologies in education. Theory and Practice of Social Development, 12, 428 - 432, 2015.

[13] Gorbunova, I. B. Music computer technologies and DIGITAL HUMANITIES, Contemporary Musical Education 2015. Proceedings of the XIV International Scientific and Practical Conference, ed. Irina B. Gorbunova, Saint Petersburg, Russia, 29 - 34, 2015.

[14] Gorbunova, I. B. Music computer technologies in training of the teacher-musician. Music Scholarship / Problemy Muzykal'noj Nauki, (16), 5-11, 2014.

[15] Gorbunova, I. B., Davletova, C. B., \& Tovpich, I. O. Electronic musical instruments in the general music education system, 15th International Conference on Education, Economics, Humanities and Interdisciplinary Studies (EEHIS18). International Conference Proceedings, ed.: Prof., Dr. Rahim Ahmadi, Prof. Kazuaki Maeda, Prof. Dr M. Plaisent. Paris, France, 139 - 144, 2018.

[16] Belov, G. G., \& Gorbunova, I. B. Music and Cybernetics. Music and Time, 11, 25-32, 2016.

[17] Gorbunova, I. B., Hiner. H., \& Zalivadny, M. S. On importance of mathematical methods in music research and education of musicians. Humanities \& Science University Journal, 11, 103-111, 2015.

[18] Gorbunova I.B., Zalivadny M.S., Tovpich I.O., Mathematical methods of research in musicology: an attempt of analyzing a material from contemporary historical heritage (Reflections on Xenakis' book 'Musiques formelles'), 15th International Conference on Education, Economics, Humanities and Interdisciplinary Studies (EEHIS-18). ICASET18, ASBES-18, EEHIS-18 International Conference Proceedings, ed.: Prof., Dr. Rahim Ahmadi, Prof. Kazuaki Maeda, Prof. Dr M. Plaisent. Paris, France, pp. 134-138 (2018).

[19] McLuhan, M. Retrieved from https://ru.wikipedia.org/wiki/ McLuhan,_Marshall

[20] Gorbunova I.B., Govorova A.A. Music computer technologies as a means of teaching the musical art for visuallyimpaired people. Int'l Conference Proceedings, Budapest (Hungary), pp. 19-22 (2018).

[21] I. Gorbunova, A. Govorova (2018) Music Computer Technologies in Informatics and Music Studies at Schools for Children with Deep Visual Impairments: From the Experience. In: Pozdniakov S., Dagiene V. (eds) Informatics in Schools. Fundamentals of Computer Science and Software Engineering. ISSEP 2018. Lecture Notes in Computer Science, vol. 11169. Springer, Cham

[22] Rags, Yu. N. Prospects of development of Informatics course in music educational institutions, Contemporary Music Education - 2003. Proceedings of the II International Research and Practical Conference, ed. Irina B. Gorbunova, Saint Petersburg, Russia, 2003. 
[23] Gorbunova, I. B. “Aesthetics: information approach" by Yu. Rags: relevance and perspectives. Theory and Practice of Social Development, 2, 86 - 90, 2015.

[24] Gorbunova, I. B., \& Hiner. H. Music Computer Technologies and Interactive Network Systems of Learning Music, IIER International Conference on Psychology, Language and Teaching (ICPLT 2018). Conference Proceedings, Oxford, United Kingdom, 2018.

[25] Gorbunova, I. B., \& Hiner. H. Interactive Network Technologies Music Learning: the Program 'Soft Way to Mozart'. Bulletin of Orel State University. Series: New Humanitarian Studies, 4 (39), 104-109, 2014.

[26] Soft Way to Mozart. Retrieved from http:// www.softmozart.com / www.softmozart.ru

[27] Gorbunova, I. B., Hiner. H., \& Zalivadny, M. S. Music computer technologies as information-translation system at the School of the Digital Age. Bulletin of Orel State University. Series: New Humanitarian Studies, 4 (39), 99-103, 2014.

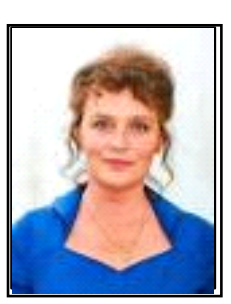

Irina B. Gorbunova was born in Saint Petersburg (Leningrad). DipMus, Special Music Higher School of the St. Petersburg State Conservatory named after N.A. Rimsky-Korsakov; BSc in Computer Science: Information Technology, Computer Science and Multimedia, Leningrad State University, Ussurisk State Pedagogical University; MA in Education, the Herzen State Pedagogical University of Russia; PhD in Information Technology and Pedagogic Sciences, the Herzen State Pedagogical University of Russia, St. Petersburg, 1989; Doctor degree: Doctor of Pedagogic Sciences and Information Technology, the Herzen State Pedagogical University of Russia, St. Petersburg, 1999. Dr. Gorbunova, Full Professor, PhD in Sc., Doctor of Pedagogic Sciences, Chief Researcher of the Educational and Methodological Laboratory Music Computer Technologies of the Herzen State Pedagogical University of Russia, St. Petersburg.

She was on a number of business trips abroad, among them working trip to the USA (1999); lecturing and giving research and practice seminars in Hungury $(2003,2005,2017)$; business trip to the UK (2016); she was a member of the Jury of national and international competitions of musical creativity, including Bridge of Friendship (Dortmund, Germany, 2011), etc. Work experience; 1990 - 2010 - Associate Professor, Professor of the Department of Information Technology of the Herzen State Pedagogical University of Russia, St. Petersburg; 2010 - present - Full Professor of the Department of Information Technology, Institute of Computer Science and Technological Education of the Herzen State Pedagogical University of Russia, St. Petersburg; 2002 - present - Chief Researcher of the Educational and Methodological Laboratory Music Computer Technologies of the Herzen State Pedagogical University of Russia, St. Petersburg. She has more than 300 scientific publications, among them are monographs Music Computer Technologies: HistoricalTheoretical and Practical Aspects, St. Petersburg: Publ. house "SMIO Press" (2007, 560 pp.) and Music Computer Technologies: The Problem of Modeling the Process of Musical Creativity, compiled with participation of S. V. Chibirev, St. Petersburg: Publ. house of the Herzen State Pedagogical University of Russia (2012, 160 pp.); course book Information Technology in Music, vol. 1 - 4: vol. 1, Architectonics of musical sound (2009, 175 pp.), vol. 2, Musical Synthesizers (2010, 205 pp.), vol. 3, Music Computer (2011, 411 pp.), Music, Mathematics and Computer Science, vol. 4, compiled with participation of Mikhail S. Zalivadny (2013, 181 pp.), St. Petersburg: Publ. house of the Herzen State Pedagogical University of Russia. Her research activities include such directions as: MCT in professional music education (as a means to expand creative opportunities); MCT in general musical education (as one of the means of education); MCT as a means of rehabilitation of people with disabilities; MCT as the new direction in preparation of specialists of humanitarian and technological profile; MCT in the field of digital arts; MCT in information technology, psychoacoustics and musical acoustics; system of training arrangements and the art of performing skills on electronic musical instruments. Her circle of interests also includes the problems of interrelation of natural and technical sciences and humanities, as well as the possibilities of applying the results of such interrelation for the purposes of music education and upbringing. She also takes part in working out the specialized software for computer music devices and in application of this software in pedagogical processes. Her developments and researches also belong to the field of musical pedagogics and musicology, musical Informatics, computer modeling of processes of musical creativity, timbre programming, art of performing skills and arrangement on electronic musical instruments, creative work in the field of computer music, mathematical methods in musicology.

Prof. Dr. Gorbunova is Chairman of the Organizing Committee of the international research and practice conference Contemporary Music Education, Chairman of the Organizing Committee of the international research and practical conference Music Computer Technologies in the System of Contemporary Education. Dr. Gorbunova is a member of the Jury of national and international competitions of musical creative works, including Electronic Palette (Saint-Petersburg), Music and Electronics (Moscow), Music of the XXI Century (Moscow / Saint-Petersburg), International Festivals and Competitions Musical Electronics and Multimedia (Moscow / Saint-Petersburg), Clarine of the XXI Century (Saint-Petersburg), The World of Art without Borders (Saint-Petersburg, Russia - Szeged, Hungary), Bridge of Friendship (Dortmund, Germany), All-Russian Competition of Electroacoustic Music DEMO (Saint-Petersburg). She is a member of Editorial Boards of International Journals: Music Scholarship / Problemy Muzykal'noj Nauki (SCOPUS), The World of Science, Culture, Education / Mir Nauki, Kul'tury, Obrazovaniya, Electronic international scientific journal of music and sound in electronic mass media, film, Internet, and multimedia MEDIAMUSIC. Prof. Dr. Gorbunova has developed first ever course in Music, called Music Computer Technologies, which has been offered under the Bachelors of Arts and Sciences (BASc),, which in 2004 carried out student recruitment in different regions and educational institutions of Russia and she also leads post-graduate courses "Music Computer Technologies in Education" available under the MA in Music Education, since 2006. Prof. Dr. Gorbunova supervises a number of doctoral and post-doctoral students (more than 30) and lectures on Music Computer Technologies and Information Technology in Music. She supervises research in various directions, among them there are: Theory and history of culture, Music Art, Information system 
and processes, Theory and methodology of professional education, Mathematical modelling, numerical methods and program systems, Theory and methods of education and upbringing (in Music, Informatics, natural sciences). The research results of Prof. Gorbunova were published in over 300 refereed publications including 48 books and 255 papers in journals and conference proceedings. Awards and honors: 2003 - Gold medal of the all-Russian Exhibition Centre (former VDNKh); 2005 - Silver medal of the all-Russian Exhibition Centre (former VDNKh); 2009 - Gold medal of the all-Russian Exhibition Centre (former VDNKh); 2009 - Diploma of the winner in the nomination «New educational technologies in ICT environment» of the all-Russian creative contest of scientific-technical solutions, educational products and services in the field of Informatization of the innovative-educational complex «Music computer technologies in the system of modern education»; 2010 - Grand Prix of International Congress-exhibition «Global Education - Education Without Borders»; 2010 - Diploma of the 11th all-Russian forum «Educational environment - 2010» for the project «Digital educational resources «Music computer technologies in education» in nomination of «Creative Competition of scientific developments, innovative solutions and programs in the field of higher vocational education» and many others; 2011 - Laureate of the Prize of the Government «For Outstanding Achievements in the Field of Higher and Secondary Professional Education»; 2013 - Honorary Worker of Higher Professional Education of the Russian Federation.

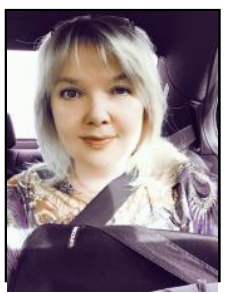

Hellene Hiner. Author and the other authors may include biographies at the end of regular papers. This author became a Member (M) of URUAR The first paragraph may contain a place and/or date of birth (list place, then date). Next, the author's educational background is listed. The degrees should be listed with type of degree in what field, which institution, city, state or country, and year degree was earned. The author's major field of study should be lower-cased.

The second paragraph uses the pronoun of the person (he or she) and not the author's last name. It lists military and work experience, including summer and fellowship jobs. Job titles are capitalized. The current job must have a location; previous positions may be listed without one. Information concerning previous publications may be included. Try not to list more than three books or published articles. The format for listing publishers of a book within the biography is: title of book (city, state: publisher name, year) similar to a reference. Current and previous research interests ends the paragraph.

The third paragraph begins with the author's title and last name (e.g., Dr. Smith, Prof. Jones, Mr. Kajor, Ms. Hunter). Finally, list any awards and work for committees and publications. If a photograph is provided, the biography will be indented around it. The photograph is placed at the top left of the biography. Personal hobbies will be deleted from the biography. 